\title{
EDUCATION FOR SUSTAINABLE DEVELOPMENT: THE US-BRAZIL SUSTAINABILITY CONSORTIUM EXPERIENCE
}

John Motloch

Eloy Fassi Casagrande Jr.

\begin{abstract}
Sustainable development (SD) integrates development with contextual systems (environmental, social, and economic) and with the elements and dynamics that characterize these systems. SD depends on an education for sustainability (EFS) that includes a focus on sustainable development that promotes successful systems management, and that pursues responsible planning and design of system elements (cities, buildings, and landscapes) in ways that sustain a positive ecobalance. This paper reviews an EFS initiative and partnering framework -- The US-Brazil Sustainability Consortium (USBSC) that integrates local and global knowledge to understand place-based systems, resource flows, and ecobalance. The USBSC is a student mobility consortium funded by the US and Brazilian departments of education. It promotes the international exchange of students in architecture, engineering and civil building, landscape architecture, urban planning, and natural resources and environmental management. It educates these students about the triple bottom line (TBL) of sustainability - environmental responsibility, social justice and economic vitality.
\end{abstract}

Keywords: Sustainable Development Education; Students Exchanging; Environmental Responsibility.

\section{Introduction}

Through much of the 20th Century, development occurred in the context of a perceived resource and energy surplus that provided the competitive advantage to lifestyles and human systems that grew fast, operated inefficiently, and maximized short-term yield (Odum, 1979). These lifestyles 
and human systems were analogous to R-type growth in biological systems. These systems also did not integrate well into their contextual systems and did not invest back into the systems upon which sustainability depended.

The best known expression of the global social-environmental problem can be found in the Club of Rome's computer study The Limits to Growth published in 1972. This extrapolated the exponential demand rates for various resources and concluded that '...the great majority of the currently important non-renewable resources will be extremely costly one hundred years from now... as long as the demand for resources continues to grow exponentially' (Meadows et al, 1972).

Twenty years late, the same scientists leaded by Donella Meadows ran a more sophisticated computer model to establish the relation between population growth; material, water and energy consumption; food production and pollution. One of the conclusions published in new study known as Beyond the Limits, is that the number of people added each year in the Earth continues to increase. Growth is still exponential, though at a slightly lower rate. The 92 million added in 1991 is equivalent to adding in that year the total of six New York Cities - or more accurately, since $90 \%$ takes place in the Third World, it is equivalent to adding in one year the total population of Mexico plus Honduras, or about eight Calcuttas. (Meadows et al, 1992).

Economic and community development during this period likewise pursued a strategy of growth. They operated inefficiently, lacked fine-tuned relationships with local and regional systems and conditions, and produced large amounts of waste.

During this period, institutions of higher education, in the U.S., Brazil, and globally, educated people to pursue these R-type strategies. Unfortunately, growing populations, advanced technologies, societal commitments to growth, and educational systems that taught us to pursue R-type growth, all combined to produce development that exceeded natural system limits (local, regional, and global) and the ability of these systems to regenerate their health and productivity.

According to the State of the World Population 2007, in 2008, the world reaches an invisible but momentous milestone: For the first time in history, more than half its human population, 3.3 billion people, will be living in urban areas. By 2030, this is expected to swell to almost 5 billion. Many of the new urbanites will be poor. Their future, the future of cities in developing 
countries, the future of humanity itself, all depend very much on decisions made now in preparation for this growth. (UNFPA, 2007).

Moreover, the planning and design communities have come to appreciate that buildings are responsible for almost half (48\%) of all energy consumption and GHG emissions in the U.S. and this percentage is even higher globally (Architecture 2030, 2008). In addition, they have also come to realize that transportation accounts for another third of energy use (in the U.S.). The professions continue to gain appreciation for the degree to which unsustainable development plays a major role in the profound global challenges we face today including global warming, dying oceans, global water shortages, collapsing economic systems, and a myriad of other crises occurring across diverse systems (environmental, social, and economic).

In the last third of the $20^{\text {th }}$ Century, the systemic advantage shifted from R-type growth to K-type systems that function in ways that optimize resources, integrate with systems, and develop fine-tuned relationships (Odum, 1979). However, due to a history of successful R-type development and major investment in R-type infrastructure, development in many parts of the world did not shift from R-type to the more sustainable K-type development. This reality was exacerbated by a higher education system that has contributed to the continued commitment to unsustainable growth by continuing to teach students to pursue R-type growth implemented through narrowly defined disciplines.

\section{The Education Challenge}

The Conference for the Environment and Development (UNCED), also called Earth Summit, Rio 92 or Eco 92, realized in Rio de Janeiro, 1992, had as a result the creation of Agenda 21. A comprehensive program of actions was summarized in this document, this includes the comment:

"One of the major challenges facing the world community, as it seeks to replace unsustainable development patterns with environmentally sound and sustainable development, is the need to activate a sense o common purpose in all sectors of society". 
There is no doubt that "education" is one of the more important sectors of society to achieve sustainable development. However we face some challenges. Because of the traditional organization of the teaching and research institutions in departments, obstacles were created to establish the interdisciplinarity, which is the basic instrument to solve the socialenvironmental problems.

It is usual to attest that many of the projects developed in isolated departments, present just part of our problems solution. The knowledge of the five more important areas that determine developed standard of a country (technique, social, economic, cultural and environmental) are seen, in general, in the educational system, in a separated way and with little interaction.

The international documents guide the EDS to a healthy and sustainable planet with social justice and environmental protection. Although about the totality of the humanity agreement with these universal principles, the guidance given to education is still for the economy. The principles of ecology are submitted to the market rules where the emphasis is given to the technology and to the economic growth, without explaining clearly about the nature limits. The incentive to the technological innovation in general is disconnected from the sustainability, focusing only in the increasing of profitability (Casagrande Jr, 2004). Most of the Brazilian and American academic students, mainly the ones from the precise sciences, attend to a educational model that makes them an 'ecological illiterate'.

In Brazil, the Law $\mathrm{n}^{\text {a }}$ 9.795, from April 27, 1999, disposes about environmental education and sets up the National Environmental Education Policy. It still has difficulties to be set up in all learning levels, from the fundamental to the superior. On the other hand, In the USA, there is also a legislation addressed to the Environmental Education that determines that the Agency of Environmental Protection (EPA) assumes the lead of increasing the American environmental literacy through the 'The National Environmental Education act of 1990'.

\section{Promoting a Societal Shift to SD}

There is a profound need for a societal shift from R-type growth to K-type systems that function in ways that optimize resources, integrate with 
systems, and develop fine-tuned relationships. Fortunately, as local, regional and global problems associated with resource scarcity, resource depletion. and resource degradation have become more pronounced, society has increasingly recognized the imperative of transitioning from R-type growth to K-type development that optimizes resources, integrates with systems, and develops fine-tuned relationships (Simonis, 1994; Grant, 2007). For example, the Chapter 36 of the Agenda 21, entitled "Teaching, Awareness and Training Promotion", called for an education for sustainable development:

\begin{abstract}
"Reorienting existing education at all levels to address sustainable development: Rethinking and revising education from nursery school through university to include more principles, skills, perspectives and values related to sustainability in each of the three realms - social, environmental, and economic - is important to our current and future societies."
\end{abstract}

Then, in 2005, the United Nation Union, through UNESCO, declared 2005-2014 as the Decade of Education for Sustainable Development (DESD 2005-2014). It advised the creation of strategies and orientation guides for action at the regional, sub-regional, national and local levels. In many parts of the world, groups are meeting to develop structures that are responsive to local environmental and cultural contexts to serve as a foundation for education for sustainable development. (UNU-IAS, 2008).

As part of the DESD 2005-2014, UNESCO and UNU (United Nations University) have established a program to set up Regional Center of Expertise (RCE). The RCE is a network of existing formal, non-formal and informal education organisations, mobilised to deliver education for sustainable development to local and regional communities. A network of RCEs worldwide will constitute the Global Learning Space for Sustainable Development in order to translate DESD 2005-2014 global objectives into the context of the local communities in which they operate. Till now, 62 RCEs have so far been acknowledged by UNU, inclunding the RCE of Curitiba, Brazil -- the only one so far organized in South America (UNU-IAS, 2008). 


\section{Promoting a Shift in Higher Education}

Sustainability can have many faces, according to the pedagogic orientation in each area and mainly when it is tried to approach it in international level, where the differences stand out because of the different historical, socialcultural and economic dimensions of the countries that compose this Planet. In the case of the Consortium Sustainability, it searches integrate teachers and students to projects, methodologies, and researches classified as sustainable and that are been developed in Brazil and in The USA.

There is a profound societal need for a shift from traditional higher education approaches to higher educational approaches that facilitate a societal shift to a sustainable future, and a shift within the planning and design professions to sustainable development. This includes a shift from teaching students to pursue R-type growth through narrowly defined disciplines, to teaching them to pursue K-type growth that integrates with local and regional environmental, cultural and economic conditions and that integrates local and global knowledge in ways that promote sustainable development.

Traditional Higher Education: Institutions of higher education, in Brazil and the U.S.A., are traditionally teaching and research institutions that are organized into relatively discrete departments. This traditional institutional structure often establishes major obstacles to interdisciplinary interaction and systems-thinking. Yet interdisciplinarity and systemsthinking are essential if we are to address today's complex problems and the interrelated myriad of crises that are occurring across diverse systems. Projects developed in isolated departments are not commonly defined so as to provide solutions with adequate interdisciplinary robustness. They often fail to integrate key disciplines and therefore fail to integrate in a sustainable way with key systems including technological, social, economic, cultural, environmental, and educational systems.

Education for Sustainability (EFS): There is a profound need for effective higher education for sustainability (EFS) that educates graduates to lead the societal shift and professional practice shift from R-type growth to K-type sustainable development. This higher education shift to EFS will, of necessity, include a focus on sustainable development that contributes to successful management of system health and productivity, and on 
responsible planning and design of system elements (cities, buildings, landscapes) in ways that sustain a positive ecobalance.

Education for Integrating Local and Global Knowledge: Globally, there is also a growing awareness of the unsustainability of development that does not integrate into local environmental, social and economic conditions. There is also a growing discontent with income divergence and the increasing number of people that struggle to participate significantly in the decisions that affect their daily lives. Both, combined with perceptions of higher education in general does not connect with the broader society (often referred to as the ivory tower syndrome), speak to the profound need for education to implement new models that integrate local and global knowledge in ways that integrate with local and regional conditions, addresses the needs of local and regional cultures, and empowers people to affect their daily lives.

\section{The US-Brazil Sustainability Consortium}

The US-Brazil Sustainability Consortium (USBSC) is currently funded by the US and Brazilian departments of education (2003-2008 funding) as a student mobility, curriculum development, and collaborative research consortium. The USBSC functions to advance sustainable development through enhanced information-flow and practical application, using an innovative model that includes interdisciplinary professional and built environment experiences and case-study research within universities, community-based centers, and cities internationally recognized for their sustainable development initiatives. In this model, national department of education program funding from the U.S. and Brazil -- the Fund for the Improvement of Post-secondary Education (FIPSE) in the U.S.; and Coordenação de Aperfeiçoamento de Pessoal de Nível Superior (CAPES) in Brazil -- facilitates development of institutional linkages, sponsorship of student exchanges, development of common curricula and research initiatives, and information dissemination.

Project funding is pursued by the USBSC to engage students in funded community-based projects and case-study research. The USBSC seeks to enhance the ability of existing degree programs to prepare graduates to lead their professions and communities to planning and design that produces sustainable development, by providing advanced theory and application 
experiences in sustainable planning and design in diverse and global contexts.

The USBSC pursues education for sustainability. It also function to bridge across departmental limits by establishing a partnership among U.S. and Brazilian universities, that integrates different disciplines including urban planning, architecture, and landscape architecture at Ball State UniversityBSU (Muncie, Indiana, USA), engineering of civil production at the Federal Technological University of Paraná-UTFPR (Curitiba, Brazil), architecture and urban planning at the Pontifical Catholic University of Rio Grande do SulPUCRS (Porto Alegre, Brazil), and architecture, civil engineering and architecture engineering, at the University of Texas-UT-Austin (Austin, Texas, USA). The Consortium also benefits from collaborating with the Center for Maximum Potential Building System-CMPBS (Austin, Texas, USA) which is a leading non- governmental organization that has been a leader in sustainable development since the 1970's.

The USBSC pursues projects that operate through a local-global collaborative model (Motloch, Pacheco and Vann, 2007; Motloch and Vann, 2007). This model is used to create local-global collaborative partnerships that pursue regional sustainability projects (Motloch, Pacheco, and Takamatsu, 2006). These partnerships link diverse groups (international and local), build a multi-sectored sense of authorship, and integrate with the dynamics of complex contextual systems to produce value-adding sustainable decisions. These collaborative partnerships apply systemsthinking to promote integration, build a locally-relevant understanding of sustainability, and promote development that is regional sustainable.

Through USBSC student exchanges, projects, research and innovative teaching methods. They learn, under the leadership of the respective USBSC coordinators and others, about SD, primarily in the urban context, that promotes environmental quality, social inclusion, and community participation. They are engaged in immersive learning experiences in the areas of environmental management, urban planning, landscape architecture, architecture, engineering, and integrated technologies; and in the pursuit of sustainable development, sustainable communities, green buildings, and sustainable sites. The USBSC affords participants (mainly students) opportunities to see sustainable development through the eyes of the host country to get a deeper understanding of SD in that country, and through a gained broader perspective, in their own country. 


\section{Systems and Sustainable Development}

This USBSC promotes development that integrates in sustainable ways with contextual systems. To achieve this goal, the USBSC provides students with experiences that help them increase their understanding of systems and systems thinking (Checkland, 1999; Motloch, 2001) and their understanding of integrated science (Wilbur, 2004). It also provides students with experiences in applying this understanding to create development that achieves sustainable relationships with contextual systems. Students gain understanding of the role of development within systems as "wholes" that function through inter-relatedness among parts, as systems within systems; and as systems that evolve over time to increasingly fine-tuned relationships. (Motloch, 2002).

The USBSC teaches students that, within limits, natural systems sustain themselves through regenerative resource flows; and that within these limits they self-organize, self-regulate, and self-manage. It also teaches students that when system conditions exceed these limits that the systems can shift to a dissipative state through which they emerge to a new system condition and productive capacity. It teaches students that growing populations, advanced technologies, societal commitments to growth, and educational systems that teach students how to pursue R-type growth, that the current human-dominated global ecosystem now exceeds natural limits and that the environmental impact of human activities now exceeds the Earth's ability to regenerate its health and productivity. This means that human-dominated ecosystems are no longer self-regulating and humankind must therefore manage local, regional and global environments (Motloch, 2003). The USBSC educates students about the major role that SD must play in this systems management for a sustainable future.

\section{SD Triple Bottom Line}

Proponents of sustainable development usually focus on sustainability's Triple Bottom Line (TBL): environmental responsibility, social justice, and economic vitality (Elkington,1998, Porritt, 2006). Most of these proponents seek to balance the TBL so as to produce development that is sustainable 
environmentally, socially, and economically. As higher education students are challenged to seek this balance, they are usually relatively unaware of the degree to which what they see as a "balance" is culturally-bounded. They are often unaware that, in the U.S., this balance is usually skewed by focusing more on environmental responsibility than on social justice or economic vitality. On the other hand SD students in Brazil usually do not see the degree to which this balance is structured through a relatively higher focus on social justice and economic vitality. By pursuing SD and EFS in the host country and culture that has a different balance of these three TBL dimensions than in the student's home country and culture, students engaged in USBSC exchanges gain a much broader and deeper understanding of sustainable development in the global sense, as well as the differences in sustainable development in the host country and in their own home country.

\section{USBSC Sustainable Development Projects}

As a condition in the Consortium, the students were guided to get a registration in a group of disciplines that gives them a global panorama of the main global social-environmental problems and the basic knowledge of the sustainable development principles, such as:

At BSU - Introduction to Sustainability, Sustainable Land Systems, Renewable Energy and Sustainable Technology, Housing and Community Design.

At UTEXAS - Design Waste Water Treatment Facilities, Structural Design in Wood, Building Environmental Systems, Air Pollution and Introduction to Environmental Engineering.

At PUCRS - Landscape Design II, Urban Planning III, Project of Building VI.

At UTFPR - Sustainable Constructions, Energetic Efficiency in Building, Industrial Ecology, GIS and Environmental Impacts Evaluation, Environmental Management.

The USBSC exchanges students have also participated in SD projects in the U.S. and Brazil. Three typical projects are featured herein, including one project initiated and mentored at each USBSC institution. Twenty three Brazilians students and thirteen American students have participated in these 
SD projects include the Greenline Eco-economic and Community Development Initiative in Central Indiana, U.S.A.; the Austin Green Building Program in Austin, Texas USA; The Green Urban Planning of Piraquara, metropolitan region of Curitiba, Brazil; the Passeio Público Revival in Curitiba, Brazil; and the Vila Nossa Senhora de Fátima in Porto Alegre, Brazil.

Greenline Eco-economic and Community Development (GEEDC)

Initiative: Through the USBSC, Brazilian students exchanging at Ball State University have participated in the GEEDC project (Truex and Motloch, 2007). This project helps educate students to meet the 2030 Challenge. According to this challenge, "Credible scientists give us 10 years to be well on our way toward global greenhouse gas (GHG) emissions reductions in order to avoid catastrophic climate change...Stabilizing emissions in the building sector and then reversing them to acceptable levels over the next ten years, is key to keeping global warming to approximately a degree centigrade $\left({ }^{\circ} \mathrm{C}\right)$ above today's level." (Architecture 2030, 2008).

To help prepare planning and design students to meet these challenges, the GEEDC project requires that all solutions engage the environment in ways that dramatically reduce the consumption of fossil fuels and that the solutions also demonstrate ecological literacy. The project seeks to enhance eco-economic development of a 70 mile portion of an existing multimodal transportation corridor. It seeks also to stimulate transit-oriented development (TOD) and eco-economic development that sustains and enhances the health and productivity of the region's land-based resources and systems. The GEEDC seeks to implement the vision of a commuter corridor powered by a regional distributed energy network that produces energy, via clean technologies, from local or regional renewable energy sources. It pursues sustainable development including an eco-economic development framework; integrated technologies and symbiotic production systems; Smart Growth including higher densities, mixed use development, infill development patterns, and walkable communities; Best Practices; and sustainable community, eco-village, and green building strategies. It pursues network- and capacity- building through development of: a database of existing resource and sustainable solutions, the development of sustainable community social and knowledge networks, and other means.

Austin Green Building Program: Brazilian students exchanging at the University of Texas (in Austin, Texas, USA) have had the opportunity of being trainees in Austin's Energy Green Building Program. This punctuation 
program (1 to 5 stars) assesses residences and buildings according for their environmental performance, energy efficiency, water consumption, use of low environmental impact materials, user health protection, and so on. USBSC students that have participated in this project have also brought these experiences back to Brazil to inform articles and white papers, and to raise the level of discourse concerning guidelines for green building and green energy programs program to be implanted in Brazil. Also Brazilian students have participated in the UTexas team of the Solar Decathlon, which every year joins more than twenty college and university teams in a competition to design, build, and operate the most attractive and energyefficient solar-powered house.

Green Urban Planning in Piraquara: Most scholars who have delved into the realm of sustainability have at least heard of Curitiba, the Brazilian city which rose out of improbable circumstances to become known as the ecological capitol of Brazil. Part of Curitiba's success as one of the world's greatest cities in terms of urban design, is that its problem solving approach tends toward sustainable thinking. The planners and politicians, like its longtime architect mayor, Jaime Lerner, helped Curitiba become what it is today. They were able to accomplish this by treating economic, social and ecological issues, not as competing problems, but rather as challenges whose solutions could be interlinked through a whole-systems approach. This integration of social, economic and environmental programs has created the positive urban synergy that makes Curitiba so special.

U.S. students exchanging at the UTFPR in Curitiba, participated in the Study Group on Technology and Environment - TEMA, that is connected to the Post-Graduation Program in Technology. These USBSC exchange students have benefited from an agreement between TEMA and COMECMetropolitan Region of Curitiba Coordination (RMC) which is the State agency responsible for integrating and organizing the execution of urban planning and public action projects on public land in the municipal districts that compose the RMC. USBSC exchange students at the UTFPR participated directly, for example, in a proposal for recovering degenerating areas in the Guarituba District of Piraquara. The aim of this project, coordinated by COMEC, was to implement leisure green areas in poor communities as a way to address water pollution problems. This project provided a unique experience to USBSC exchange students, where they had to address the Brazilian reality. It also provided experiences that the students disseminated 
in scientific articles and presentations at international conferences (Wendelin, Casagrande Jr. and Motloch, 2005).

Passeio Público Revival: U.S. students exchanging at the UTFPR in Curitiba had the opportunity to participate in a number of projects including the 'Passeio Público' revival. This project, developed according to sustainable principles, is located in the oldest park in Curitiba. With the information collected and following the objectives laid out by the USBSC exchanging students, recommendations for a renovation of Passeio Público were made. The renovation should present Passeio Público with a fresh image to the Curitibanos, increasing activity within and surrounding the park. The proposals intend to increase economic activity, to provide opportunities for education on sustainability, to improve the conditions of the environment and to be an example of sustainable construction.

The Passeio Público is also the site of the municipality's first Zoo. Since the park had received little improvement for a long period of time, U.S. students exchanging in the USBSC proposed construction in the park of a Educational Center for Sustainability. Their proposal connected this Center to the State School of Paraná that is located in the same neighborhood, and to "an amphitheater, an event center for art exhibitions connected to the environment, a cyber-coffee house, a playground made by recyclable materials, the creation of a biological cleaning system for the lakes in the park, a new design for the few cages that are still there for few animals, besides the integration of a organic product fair, as a tool for the environmental education". (Woodward, Casagrande Jr, Calderwood and Vessel, 2006)

Vila Nossa Senhora de Fátima: Vila Nossa Senhora de Fátima is an economically distressed informal community of Porto Alegre, near the PUCRS campus. Through the USBSC, U.S. students exchanging at the Pontifical Catholic University of Rio Grande do Sul - PUCRS in Porto Alegre, Brazil, have participated with PUCRS students in a risk management and Best Practice demonstration program in the Villa (Bauer and Motloch 2007). This program includes an urban space / quality of life pilot project, social programs that help prepare the community for services and facilities implementation, and sustainability initiatives to mainstream risk reduction for residents through projects including constructed wetlands, environmental mitigation, ecological restoration, and sustainable development that 
enhances safety, protects property, empowers residents, and reduces poverty.

Vila Nossa Senhora de Fátima began with the 1953 spontaneously occupation by poor people of an area within Port Alegre that is near the PUCRS campus. The current conditions of the Vila, based on 2007 figures, include a population of 11,770 people that are segregated, socially and spatially, from the formal community by high density ( 279 people/hectare), and by a lack of urban planning and infrastructure ( $64 \%$ of houses have no lights, $34 \%$ have no water, and $80 \%$ have no sewage system). The community offers many opportunities for risk reduction including the relocation of houses from eroding stream banks and other high-risk areas, ecological restoration and urban ecology projects that improve quality of life, and enhanced community organization and empowerment.

Many organizations and other outside partners have worked to empower the favela through workshops and community-participation training. In addition, social programs have prepared residents for anticipated infrastructure implementation. In addition, the Local Integrated Development Plan (PDLI) pilot project has employed global-local partnering including the METROPLAN State Foundation of Metropolitan Urban Planning of Porto Alegre, the GTZ German NGO, and residents, to identify community problems and potentials, empowerment instruments, and management opportunities (Bauer and Motloch 2007). These programs have improved community awareness and a community sewage system has been implemented. However, the programs have not significantly increased understanding of the environmental challenges and associated risks faced buy the community. Despite high risks of collapse, houses near the stream have not been relocated due to limited economic resources. The community also has a major need for an educational and technical training program to raise understanding of how to retrofit the community, houses and urban landscape in sustainable ways.

Through the US-Brazil Sustainability Consortium, PUC-RS (Porto Alegre, Brazil) and BSU (Indiana, USA) are collaborating with agencies and residents to pursue cost-effective projects that apply ecological models and principles (such as integrating with life cycle flows and ecological dynamics) to produce sustainable development that is environmentally responsible, socially just, and economically viable solutions appropriate in the physical, social and economic reality of the informal Vila Nossa Senhora de Fátima community. 
They are doing so through a series of ecological restoration, constructed wetlands, streambank restoration, and related projects proposed by the Consortium to "manage risk, mitigate water pollution, reduce erosion and sedimentation, reduce hazards, enhance safety and health, protect houses and property, generate jobs, and enhance income of local residents." (Bauer and Motloch, 2007)

\section{Sustainable Development Outcomes}

In the four years since its inception, the USBSC has provided students that have exchanged with a deeper understanding of sustainability in general and of sustainable development in particular. Through pursuing sustainable development projects in environmental, social, and economic contexts that era different from the ones in which these students have previously studied, USBSC exchange students have learned to understand sustainable development through the reality of another culture. They have also, in the process, become acutely aware of the culturally-bounded paradigm in their home country and its implications to sustainable development. Most importantly, they have been sensitized to the reality that SD education bounded by any cultural paradigm is not exportable to other environmental, cultural or economic contexts or regions. They have become aware of localglobal collaborative models and collaborative partnerships that can integrate local and global knowledge to understand place-based systems and that can realize local and regionally appropriate sustainable development.

\section{Bibliography}

Architecture 2030. The 2030 Challenge. Acess in: http://www.architecture2030.org/2030_challenge/index.html

Bauer, R.; Motloch, J. Vila Nossa Senhora de Fátima: Global-Local Partnering for Place-based Risk-Managing Development. $9^{\text {th }}$ Annual technology policy and innovation conference. Lund, 2007.

LEMANN, Mariana. O sonho acabou? In: Você S / A. São Paulo, v. 4, n. 41, p. 20-27, nov. 2001. 
Casagrande Jr., E. F. Inovação tecnológica e sustentabilidade: possíveis ferramentas para uma necessária interface. Revista Educação \& Tecnologia Curitiba, v. 8, p. 97-109, Programa de Pós-graduação em Tecnologia, Universidade Tecnológica Federal do Paraná, 2004.

Casagrande Jr., E. F.; Bauer R.; Agudelo, L. P. P. The US-Brazil Sustainability Consortium CAPES / FIPSE: Educating for a Sustainable World. Brasilia: The U.S.-Brazil Higher Education Consortia Program Experience, 2006.

Grant, G.B. Knowledge Infrastructure for Industrial Symbiosis: progress in information and communication technology. Dissertation (Master) - Purdue University. West Lafayette, 2006.

Woodward, K.; Casagrande Jr., E. F.; Calderwood, T, Vessel S. Demonstration Center for Sustainable Practices: The renovation of Passeio Público, Curitiba, Brasil. Sustainable in the Americas Conference: Brazil, Canada, México, and the U.S. Austin: The University of Texas at Austin, September 18, 2006.

Meadows, D. H; Meadows, D. L.; Randers, J.; Behrens, W.W. The limits to Growth. New York: Universe Books, 1972.

Meadows, D. H.; Meadows, D. L.; Randers, J. Beyond the limits. London: Earthscan Publications, 1992.

Motloch, J.; Fisk, P.; Ramina, R.; Pacheco, P. Innovation and Knowledgesharing Across Public and Private Sectors, Chapter 16 in Connecting People, Ideas and Resources Across Communities, Purdue University Press, 2007.

Motloch, J.L.; Pacheco, P.D.; Vann, J. W. Sustainability for the Americas: Building the American Network of Sustainability Consortia, International Journal for Sustainability in Higher Education, vol. 8 (issue 2), 183-197. 2007.

Motloch J.L. and Vann, J. Local-global Collaborative Partnering for Regional Sustainability, 13th Annual International Sustainable Development Research 
Conference Track 10: How can industrial ecology contribute to regional sustainability? Vasteras, Sweden, 2007.

Motloch, J.L.; Pacheco, P.D.; Takamatsu, A.A. Technology Transfer through Local-Global Partnering: Lessons from the Sustainability for the Americas initiative, Lodz, Poland, 2006.

Odum H.T. Paper read at the Florida Conference on Energy. Gainesville, $\mathrm{FL}, 1981$.

Simonis, U. E. Industrial Restructuring in Industrial Countries. Industrial Metabolism: Restructuring for Sustainable Development. U. E. S. Robert U. Ayres. Tokyo, United Nations University Press, 1994.

Truex and Motloch. Greenline Eco-economic and Community Development Initiative by the Community-Based Projects Programs (CBP) and Land Design Institute (LDI) in partnership with the Center for Energy Research Education and Service (CERES) and Building Futures Institute (BFI), Ball State University, 2007.

UNFPA. The State of the World Population 2007. The United Nations Population Fund, Acess in: http://www.unfpa.org/swp/2007/english/introduction.html

UNU-IAS (United Nations University, Institute of Advanced Studies), Education for Sustainable Development (ESD). Acess in: http://www.ias.unu.edu/sub_page.aspx?catID=108\&ddlID=182, 2008.

Wendelin, S.; Casagrande Jr, E.F.; Motloch, J. The Environmental and Social Needs of the Metropolitan Region of Curitiba: An Integrated Solution of the US-Brazil Sustainability Consortium. $5^{\text {th }}$ Annual Meeting of the US-Brazil Consortium Program. Washington, 2005. 